\title{
Increased patellar bone tracer uptake in preoperative SPECT/CT before medial opening high tibial osteotomy correlates with inferior clinical outcome
}

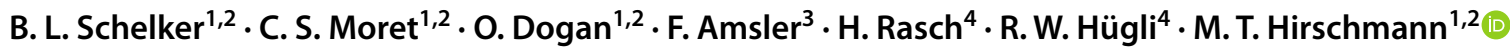

Received: 15 March 2021 / Accepted: 20 August 2021 / Published online: 5 September 2021

(C) The Author(s) 2021

\begin{abstract}
Purpose The purpose of this study was to investigate whether specific bone tracer uptake (BTU) patterns on preoperative SPECT/CT could predict which patients with varus alignment and medial overload would particularly benefit from medial opening-wedge high tibial osteotomy (MOWHTO). It was the hypothesis that an increased preoperative BTU relative to the reference BTU of the femur on SPECT/CT in the lateral and patellar compartments of the knee are predictive factors for inferior clinical outcome and that the clinical outcome correlates with the extent of alignment correction.

Methods Twenty-three knees from 22 patients who underwent MOWHTO for medial compartment overload were investigated preoperatively using Tc-99m-SPECT/CT. BTU was quantified and localised to specific joint areas according to a previously validated scheme. Pre- and postoperative mechanical alignment was measured. Clinical outcome was assessed at a median of 24 months (range 11-30) after MOWHTO by collecting the WOMAC score.

Results Significant correlations between BTU in the patellar area and the total WOMAC score and its subcategories pain and stiffness were found. Thus, BTU in the 1sPat area (superior lateral patellar compartment) correlated with total WOMAC (rho $=0.43, p=0.04)$, pain subcategory ( $r h o=0.43, p=0.04)$, and stiffness subcategory (rho $=0.59, p=0.003$ ). No significant correlations were found between alignment correction, age, gender and WOMAC.

Conclusion This study highlights the role of preoperative SPECT in modern knee surgery to obtain information about the loading pattern on different compartments of the knee. Despite the limited number of participants, the present study shows that a preoperative SPECT/CT scan can help the treating surgeons to identify patients who may be at risk of inferior clinical outcome if an MOWHTO is considered, as an elevated BTU in the patellar region on preoperative SPECT/CT appears to be a potential risk factor for postoperative pain and stiffness.
\end{abstract}

Level of evidence Level III.

Keywords Knee $\cdot$ Outcome $\cdot$ High tibial osteotomy $\cdot$ Medial compartment osteoarthritis $\cdot$ SPECT/CT $\cdot$ Alignment

M. T. Hirschmann

michael.hirschmann@unibas.ch

1 Department of Orthopaedic Surgery and Traumatology, Kantonsspital Baselland (Bruderholz, Liestal, Laufen), 4101 Bruderholz, Switzerland

2 University of Basel, Basel, Switzerland

3 Amsler Consulting, Basel, Switzerland

4 Institute of Radiology and Nuclear Medicine, Kantonsspital Baselland (Bruderholz, Liestal, Laufen), 4101 Bruderholz, Switzerland

\section{Introduction}

One cause of medial compartmental osteoarthritis (OA) is varus alignment of the lower limb. In a varus knee, the weight-bearing axis runs medially through the knee and results in the majority of the load being transferred to the medial compartment [7,22]. To shift the load from the medial to the lateral compartment of the knee and thus relieve pain and delay the progression of $\mathrm{OA}$, a valgus high tibial osteotomy might be considered [9]. To date, medial opening-wedge high tibial osteotomy (MOWHTO) is the method of choice when compared with lateral closing-wedge HTO due to its less demanding technique and reduced complication rate $[18,35]$. There is a considerable variation in 
the literature regarding the ideal postoperative mechanical alignment. The majority of authors indicate that correction should extend beyond the neutral position [16, 34]. Nevertheless, others suggest that overcorrection leads to the progression of degenerative changes in the lateral compartment of the knee [14, 23, 33]. Hirschmann et al. showed that single-photon emission computed tomography/computed tomography (SPECT/CT) can be used to visualise and quantify the loading pattern of the knee in comparison to the mechanical alignment [11]. Furthermore, Mucha et al. were able to show that the load in the medial compartment decreased in patients with varus alignment after MOWHTO. The decrease in load resulted in a decrease in bone tracer uptake (BTU) and was correlated with a reduction in pain and stiffness in patients. Conversely, a higher postoperative BTU has been shown to be associated with increased pain [26].

The primary purpose of the study was to investigate whether findings in SPECT/CT can predict which patients with varus alignment and medial overload after MOWHTO will particularly benefit from MOWHTO and which will not. It was hypothesised that an increased preoperative BTU on SPECT/CT in the lateral and patellar compartments is a predictive factor for a worse outcome and therefore patients with such finding benefit less from MOWHTO. The secondary objective was to evaluate the clinical outcome compared to the amount of correction of the mechanical alignment. It was hypothesised that the postoperative shift of the mechanical axis may lead to additional loading on the left compartment and thus cause pain and worse clinical outcome, especially in case of overcorrection.

\section{Materials and methods}

IRB approval was obtained from the local ethics committee of Northwestern Switzerland (EKNZ, application number 2016-01349). All procedures performed were in accordance with the ethical standards of the responsible committee and with the 1964 Declaration of Helsinki and its later amendments. Informed consent was obtained from all individual participants prior to enrolment in the study.

The hospital archive was searched for patients who underwent MOWHTO for medial joint compartment overload due to mechanical varus alignment. Twenty-three knees from 22 consecutive patients were retrospectively included in this study. In all patients, a SPECT/CT of the affected joint was performed preoperatively. The mean age was $47 \pm 10$ years at the time of surgery. The enrolled cohort was composed of 18 males (19 knees) and 4 females (4 knees) (Table 1).

Exclusion criteria were post-traumatic OA, open growth plates, use of corticosteroids within the last 6 months, osteonecrosis, osteochondritis dissecans, chondrocalcinosis of
Table 1 Baseline characteristics

\begin{tabular}{llr}
\hline & Mean (SD) & $N$ knees $(\%)$ \\
\hline Age OP & $46,5( \pm 10.4)$ & \\
Sex & & $19(82.6)$ \\
Male & $4(17.4)$ \\
Female & \\
Side & $13(56.5)$ \\
Left & $10(43.5)$ \\
Right & \\
\hline
\end{tabular}

the meniscus, tumour diseases, Paget's disease, knee joint infection, periarticular fracture, neuropathic arthropathy, reactive arthritis, gout, as well as patients with dementia or other limitations who could not complete the clinical outcome questionnaire.

MOWHTO was performed by experienced orthopaedic surgeons using published standard surgical techniques with the Tomofix plate (Synthes, Oberdorf, Switzerland) or the Numelock plate (Stryker, Selzach, Switzerland) [17, 21, 28, 30]. Preoperative SPECT/CT was performed using a hybrid system (Symbia T16 Siemens, Erlangen, Germany) and using 99mTc-HDP 500-7000 MBq (Mallinckrodt, Wollerau, Switzerland) as radionuclide. Scintigraphic images were acquired in three phases, the perfusion phase immediately after injection, the blood pool phase 2-5 min after injection and the delayed metabolic phase $2-3 \mathrm{~h}$ after injection. The SPECT/CT was performed with a matrix of $128 \times 128$, an angle step of 32 degrees and a time per frame of $25 \mathrm{~s}$. 3D reconstruction of the images was made.

The BTU was analysed using custom software (IntroSPECT, OrthoImagingSolutions Ltd., London, UK) which is able to localise the BTU according to a previously validated and standardised localisation scheme [12, 27]. The scheme defines 9 femoral, 8 patellar and 13 tibial zones to map the BTU volume (Figs. 1, 2, 3, 4). Each zone of the femur and tibia is represented with a number (1-lateral,--medial, 3-tibial) and two small letters ( $\mathrm{a}$ - anterior, $\mathrm{p}$ - posterior, $\mathrm{i}$-inferior, s-superior). The patella is divided into four zones (2s-superomedial, $1 \mathrm{~s}$-superolateral, $2 \mathrm{i}$ - inferomedial and $1 \mathrm{i}-$ inferolateral). Values for each were recorded and presented as a numerical value (mean \pm standard deviation, median and range) in relation to the reference recording of the bone shaft of the femur.

Mechanical alignment was measured as the angle between a line connecting the femoral head to the intercondylar notch and with a line connecting the centre of the talus to the tibial eminence. It was measured by SPECT/CT using the previously validated software (Orthoexpert v1.15@, OrthoImagingSolutions Ltd, London, UK) [31].

All measurements were performed twice by two independent observers at an interval of 4 weeks. Both 
Fig. 1 The mapping scheme used for localization of areas uptake values (F $1 / 4$ femur; $\mathrm{T}$ 1/4 tibia; P $1 / 4$ patella; 1 1/4 lateral; 2 1/4 medial; 3 1/4 tibial intercondylar area; s $1 / 4$ superior; i $1 / 4$ inferior; a $1 / 4$ anterior; p $1 / 4$ p of increased SPECT/CT tracer
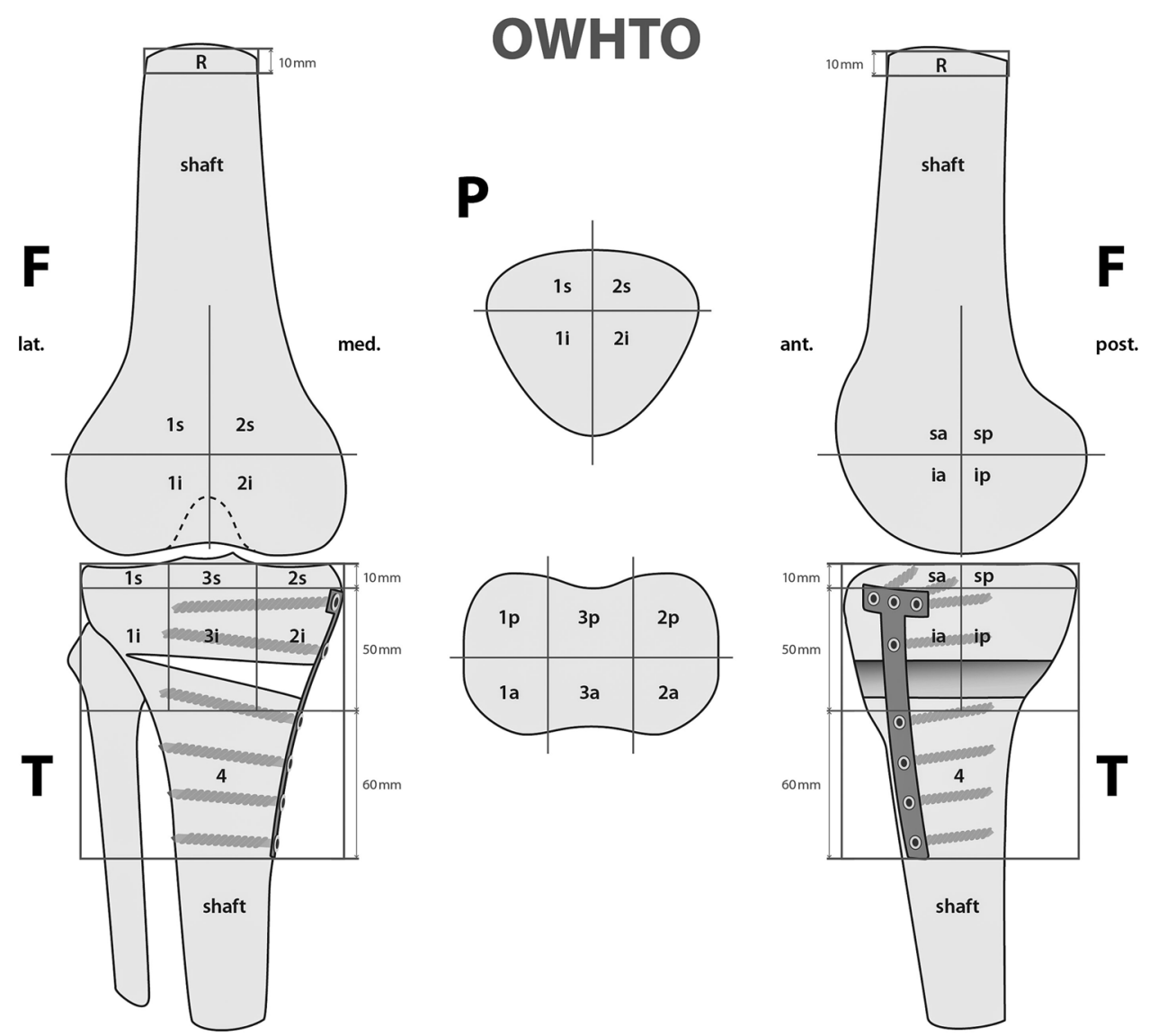

Fig. 2 Relationship between total WOMAC score and BTU in area $1 \mathrm{sPat}$

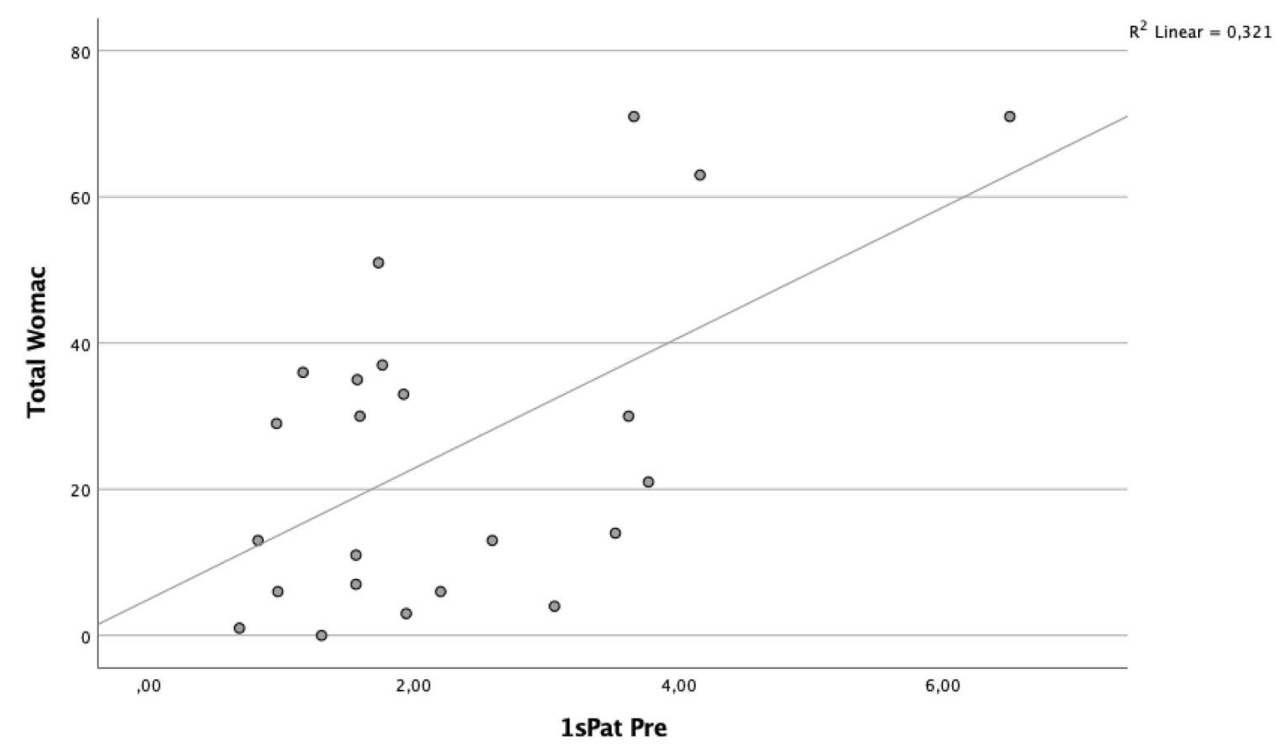

observers were blinded to the results of the previous observations. The localisation scheme showed very high inter- and intraobserver reliability (OR) (intra-class correlation coefficient (ICC) $>0.9$ ) for the BTU and localisation measurements. There was also a strong inter-observer agreement for the mechanical alignment measurements (an inter-OR of ICC $=0.99$ and an intra-OR of ICC $=0.98$ ).

The clinical outcome was assessed at a median of 24 months (range 11-30 months) post-surgery using the Western Ontario and McMaster Universities Osteoarthritis 
Fig. 3 Relationship between total WOMAC pain score and BTU in area $1 \mathrm{sPat}$
Fig. 4 Relationship between WOMAC stiffness score and BTU in area 1sPat
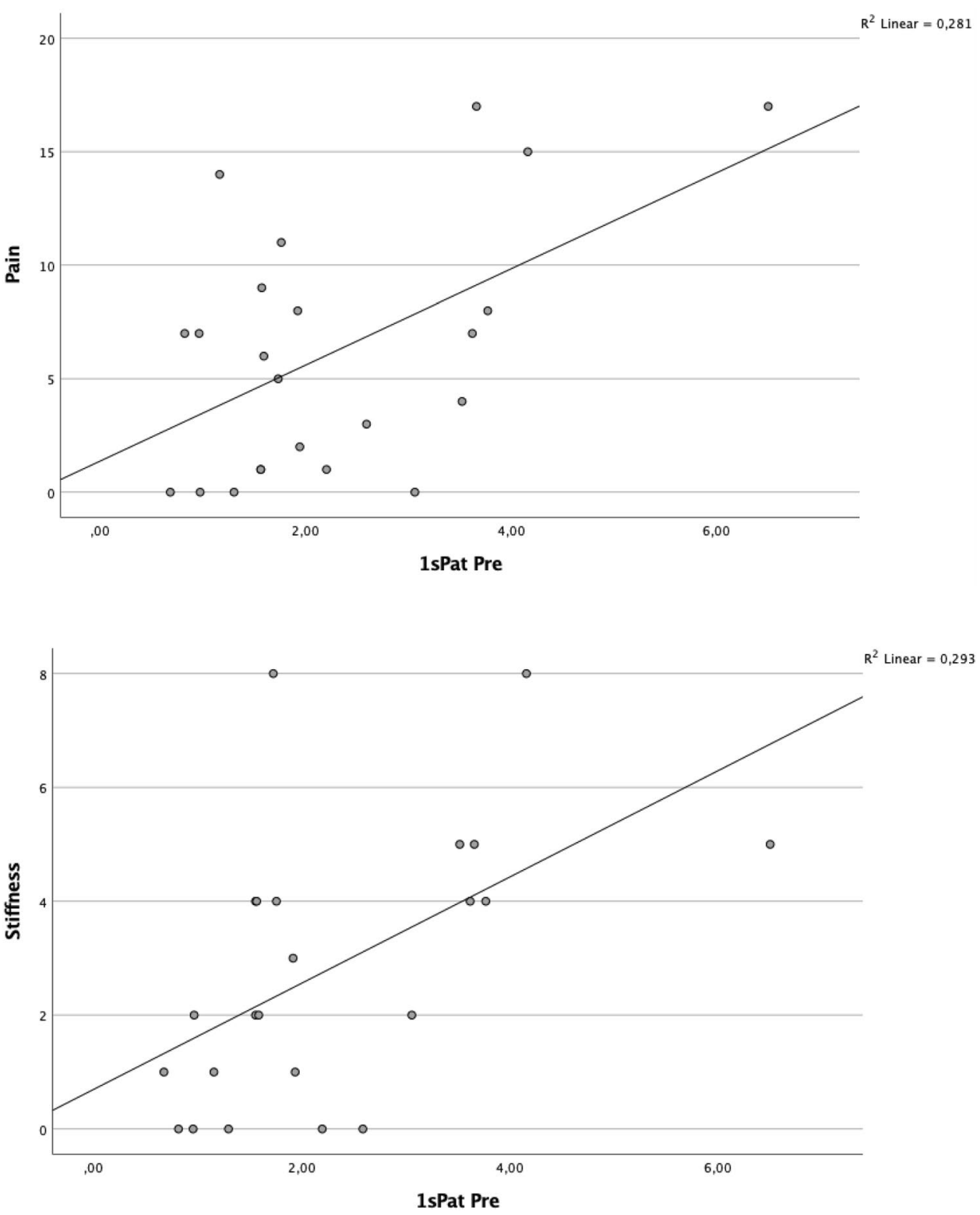

Index (WOMAC) questionnaire. The WOMAC score contains 24 questions and is able to assess the effects of osteoarthritis of the knee joint in terms of pain, stiffness and the daily activities of the patient [38]. The WOMAC score has been used in the past in several studies as a patient-reported outcome measure (PROM) to evaluate clinical outcome after HTO $[1,13]$.

\section{Statistical analysis}

Data were analysed using SPSS 17.0 and 27.0 (SPSS, Chicago, IL). Continuous variables were described using means and standard deviations or medians and ranges.
Non-parametric Spearman correlations were used to calculate associations between mechanical axis correction, preoperative BTU uptake and WOMAC score. A nonparametric test (Wilcoxon) was used to compare the BTU of preoperative SPECT/CT of specific localizations. ETA correlations were determined for correlations between sex and WOMAC score. For all analyses, a $p$ value less than 0.05 was considered statistically significant. A post hoc power analysis tested that for the number of subjects given, $n=23$, a correlation of rho $\geq 0.55$ with a power of $80 \%$ can be found, considering a two-tailed $p$ value less than 0.05 . With a one-tailed $p$ value less than 0.05 , a correlation of rho $\geq 0.50$ can be found with a power of $80 \%$. 


\section{Results}

Compared to the lateral compartment, the medial compartment shows significantly higher BTU (Table 2). Details of the preoperative and postoperative mechanical axis and as well as their difference are provided in Table 3 . The mean values for the WOMAC total score and the subcategories pain, stiffness and daily activities are also shown in Table 3 .

\section{Correlation between alignment and clinical outcome}

There was no significant correlation between the preoperative mechanical axis and the postoperative WOMAC score.
Similarly, there was no significant correlation between the postoperative mechanical axis and the WOMAC score, nor was there a significant correlation between the axis difference and the WOMAC score. The results of the correlation analysis are provided in Table 4.

\section{Correlation between BTU and clinical outcome}

A significant correlation was found between BTU in the patellar region and clinical outcome (Table 5, Figs. 2 and 3). Specifically, the superior lateral area of the patella (1sPat) and the different subcategories of the WOMAC, pain rho $=0.43$ $(p=0.04$, Fig. 5$)$, stiffness rho $=0.59(p=0.003$, Fig. 6$)$ and the total WOMAC score rho $=0.43(p=0.042$, Fig. 4$)$ correlated.
Table 2 Comparison of BTU of medial $(=2)$ and lateral $(=1)$ compartments and Wilcoxon rank sum test

\begin{tabular}{|c|c|c|c|c|c|}
\hline & \multicolumn{2}{|l|}{ Lateral } & \multicolumn{2}{|l|}{ Medial } & \multirow[t]{2}{*}{$p$} \\
\hline & Mean (SD) & Min, $25 \% 50 \% 75 \% \max$ & Mean (SD) & Min, $25 \% 50 \% 75 \% \max$ & \\
\hline $\mathrm{saFe}$ & $1.77(0.64)$ & $1.00,1.36,1.56,2.05,3.70$ & $1.77(0.59)$ & $1.03,1.31,1.66,2.12,3.20$ & ns \\
\hline $\mathrm{spFe}$ & $2.01(1.29)$ & $1.24,1.4,1.49,2.37,7.44$ & $2.10(1.04)$ & $0.98,1.39,1.74,2.50,4.91$ & ns \\
\hline $\mathrm{iaFe}$ & $2.03(0.87)$ & $0.88,1.35,1.62,2.64,4.28$ & $3.30(1.66)$ & $1.33,1.74,2.95,4.52,7.27$ & 0.001 \\
\hline ipFe & $2.02(1.26)$ & $0.83,1.35,1.65,2.19,6.96$ & $3.79(1.99)$ & $1.28,2.10,3.58,4.93,9.31$ & 0.000 \\
\hline saTib & $1.56(0.61)$ & $0.92,1.12,1.32,1.98,3.34$ & $2.86(1.65)$ & $1.24,1.73,2.47,3.35,8.49$ & 0.000 \\
\hline spTib & $1.76(0.50)$ & $1.13,1.44,1.57,2.08,2.97$ & $3.41(1.97)$ & $1.52,1.90,3.06,4.10,10.47$ & 0.000 \\
\hline iaTib & $1.83(0.68)$ & $0.58,1.21,1.80,2.21,3.21$ & $1.70(1.02)$ & $0.44,1.15,1.55,1.80,5.12$ & ns \\
\hline ipTib & $1.62(0.44)$ & $1.00,1.35,1.48,1.82,2.64$ & $2.29(1.39)$ & $0.99,1.44,1.95,2.75,7.49$ & 0.013 \\
\hline
\end{tabular}

\begin{tabular}{lcrllllllll}
\hline & $N$ & Mean & Median & SD & Min & Max & \multicolumn{2}{l}{ Percentile } \\
\cline { 7 - 10 } & & & & & & & & 25 & 50 & 75 \\
\hline MecAx Pre & 23 & 2.73 & 3.00 & 2.86 & -2.30 & 7.30 & 0 & 3 & 5 \\
MecAx Post & 23 & -2.83 & -2.9 & 2.54 & -9.8 & 1.3 & -4.3 & -2.9 & -1 \\
MecAx Diff & 23 & -5.53 & -5.88 & 2.77 & -11.38 & 2 & -7.5 & -5.88 & -4 \\
Pain & 23 & 6.22 & 6 & 5.56 & 0 & 17 & 1 & 6 & 9 \\
Stiffness & 23 & 2.83 & 2 & 2.41 & 0 & 8 & 1 & 2 & 4 \\
Daily activities & 23 & 17.43 & 19 & 16.93 & 0 & 57 & 4 & 19 & 22 \\
Total WOMAC & 23 & 25.43 & 21 & 21.99 & 0 & 71 & 6 & 21 & 36.00 \\
\hline
\end{tabular}

Table 3 Mean values and standard deviation of alignment and postoperative WOMAC score

Table 4 Spearman correlations between mechanical alignment and WOMAC; $* p<0.05$. ${ }^{* *} p<0.01 . * * * p<0.001$

\begin{tabular}{|c|c|c|c|c|c|c|c|}
\hline Spearman-Rho & MecAx Pre & MecAx Post & MecAx Diff & Pain mean & Stiffness mean & $\begin{array}{l}\text { Daily activi- } \\
\text { ties mean }\end{array}$ & $\begin{array}{l}\text { Total } \\
\text { WOMAC } \\
\text { mean }\end{array}$ \\
\hline MecAx Pre & 1.00 & $0.42 *$ & $-0.56 * *$ & -0.26 & -0.18 & -0.03 & -0.15 \\
\hline MecAx Post & $0.42 *$ & 1.00 & 0.41 & -0.34 & -0.25 & -0.23 & -0.33 \\
\hline MecAx Diff & $-0.56 * *$ & 0.41 & 1.00 & -0.08 & -0.06 & -0.15 & -0.17 \\
\hline Pain mean & -0.26 & -0.34 & -0.08 & 1.00 & $0.49 *$ & $0.86^{* *}$ & $0.91 * *$ \\
\hline Stiffness mean & -0.18 & -0.25 & -0.06 & $0.49 *$ & 1.00 & $0.57 * *$ & $0.67 * *$ \\
\hline Daily activities mean & -0.03 & -0.23 & -0.15 & $0.86^{* *}$ & $0.57 * *$ & 1.00 & $0.95^{* *}$ \\
\hline Total WOMAC mean & -0.15 & -0.33 & -0.17 & $0.91 * *$ & $0.67 * *$ & $0.95 * *$ & 1.00 \\
\hline
\end{tabular}


Table 5 Spearman correlations between BTU, alignment and WOMAC score; ${ }^{*} p<0.05 .{ }^{* *} p<0.01 . * * * p<0.001$

\begin{tabular}{|c|c|c|c|c|c|c|c|}
\hline Spearman-Rho & MecAx Pre & MecAx Post & MecAx Diff & Pain & Stiffness & Daily activities & Total WOMAC \\
\hline 1saFe Pre & -0.08 & 0.34 & $0.42 *$ & 0.00 & $0.45^{*}$ & 0.04 & 0.09 \\
\hline 2saFe Pre & -0.09 & 0.30 & 0.41 & -0.31 & -0.13 & -0.24 & -0.30 \\
\hline 1spFe Pre & 0.13 & $0.42 *$ & 0.11 & -0.05 & 0.16 & 0.03 & 0.00 \\
\hline $2 \mathrm{spFe}$ Pre & 0.12 & 0.35 & 0.18 & -0.11 & 0.14 & -0.05 & -0.04 \\
\hline 1iaFe Pre & 0.28 & 0.39 & 0.07 & 0.05 & 0.09 & -0.02 & 0.00 \\
\hline 2iaFe Pre & 0.01 & 0.14 & 0.18 & -0.32 & -0.23 & -0.31 & -0.37 \\
\hline 1ipFe Pre & 0.24 & $0.54 * *$ & 0.15 & 0.05 & 0.13 & 0.09 & 0.08 \\
\hline 2ipFe Pre & 0.04 & 0.09 & 0.06 & -0.33 & -0.12 & -0.40 & -0.37 \\
\hline 1sPat Pre & -0.31 & 0.05 & 0.31 & $0.43 *$ & $0.59 * *$ & 0.38 & $0.43 *$ \\
\hline 2sPat Pre & -0.31 & -0.03 & 0.23 & 0.26 & $0.54 * *$ & 0.24 & 0.29 \\
\hline 1iPat Pre & -0.20 & 0.02 & 0.24 & 0.26 & $0.58 * *$ & 0.25 & 0.31 \\
\hline 2iPat Pre & -0.28 & 0.02 & 0.34 & 0.09 & $0.43 *$ & 0.08 & 0.14 \\
\hline 1saTib Pre & -0.11 & 0.18 & 0.34 & 0.22 & 0.16 & 0.06 & 0.09 \\
\hline 3saTib Pre & -0.10 & 0.29 & 0.36 & 0.12 & 0.14 & 0.02 & 0.11 \\
\hline 2saTib Pre & -0.09 & 0.25 & 0.29 & -0.10 & -0.13 & -0.19 & -0.18 \\
\hline 1spTib Pre & -0.10 & 0.30 & 0.33 & 0.11 & 0.07 & 0.02 & 0.02 \\
\hline 3spTib Pre & -0.04 & 0.18 & 0.29 & 0.17 & -0.10 & 0.10 & 0.12 \\
\hline 2spTib Pre & 0.23 & 0.38 & 0.12 & -0.30 & -0.16 & -0.33 & -0.30 \\
\hline 1iaTib Pre & -0.09 & 0.26 & 0.26 & 0.29 & 0.33 & 0.37 & 0.35 \\
\hline 3iaTib Pre & -0.07 & 0.37 & 0.37 & 0.18 & 0.29 & 0.23 & 0.22 \\
\hline 2iaTib Pre & -0.05 & $0.58 * *$ & $0.49 *$ & 0.02 & -0.12 & -0.03 & -0.03 \\
\hline 1ipTib Pre & -0.04 & 0.17 & 0.21 & 0.05 & -0.02 & -0.05 & -0.08 \\
\hline 3ipTib Pre & -.02 & 0.41 & 0.39 & 0.14 & -0.13 & 0.02 & 0.02 \\
\hline 2ipTib Pre & 0.21 & $0.42 *$ & 0.22 & -0.18 & -0.18 & -0.17 & -0.20 \\
\hline 4Tib Pre & 0.06 & $0.65 * *$ & $0.49 *$ & -0.03 & -0.15 & -0.04 & -0.13 \\
\hline
\end{tabular}

Fig. 5 Relationship between WOMAC stiffness score and BTU in area 1iPat

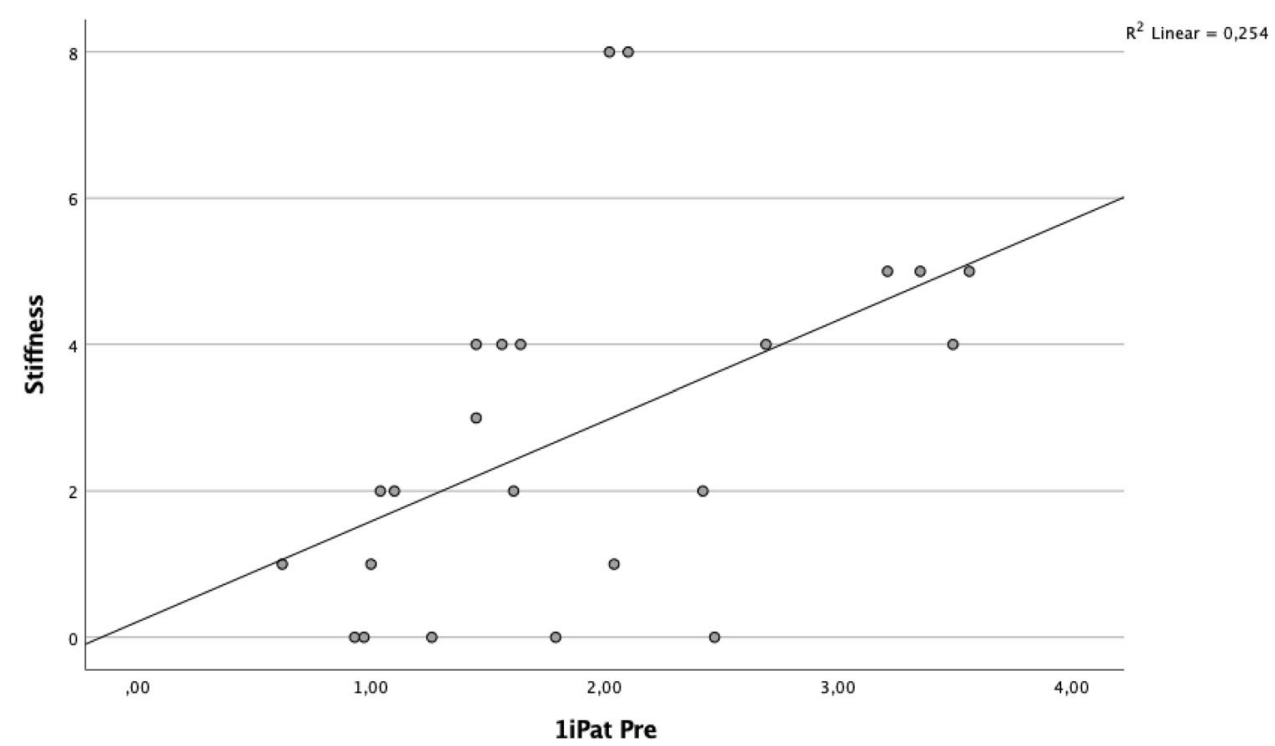

area of the patella (2sPat) correlated with stiffness rho $=0.54$
The inferior lateral area of the patella (1iPat) correlated with stiffness rho $=0.58(p=0.004$, Fig. 7). The superior medial 
Fig. 6 Relationship between WOMAC stiffness score and BTU in area 2sPat

Fig. 7 Relationship between WOMAC stiffness score and $\mathrm{BTU}$ in area $2 \mathrm{iPat}$
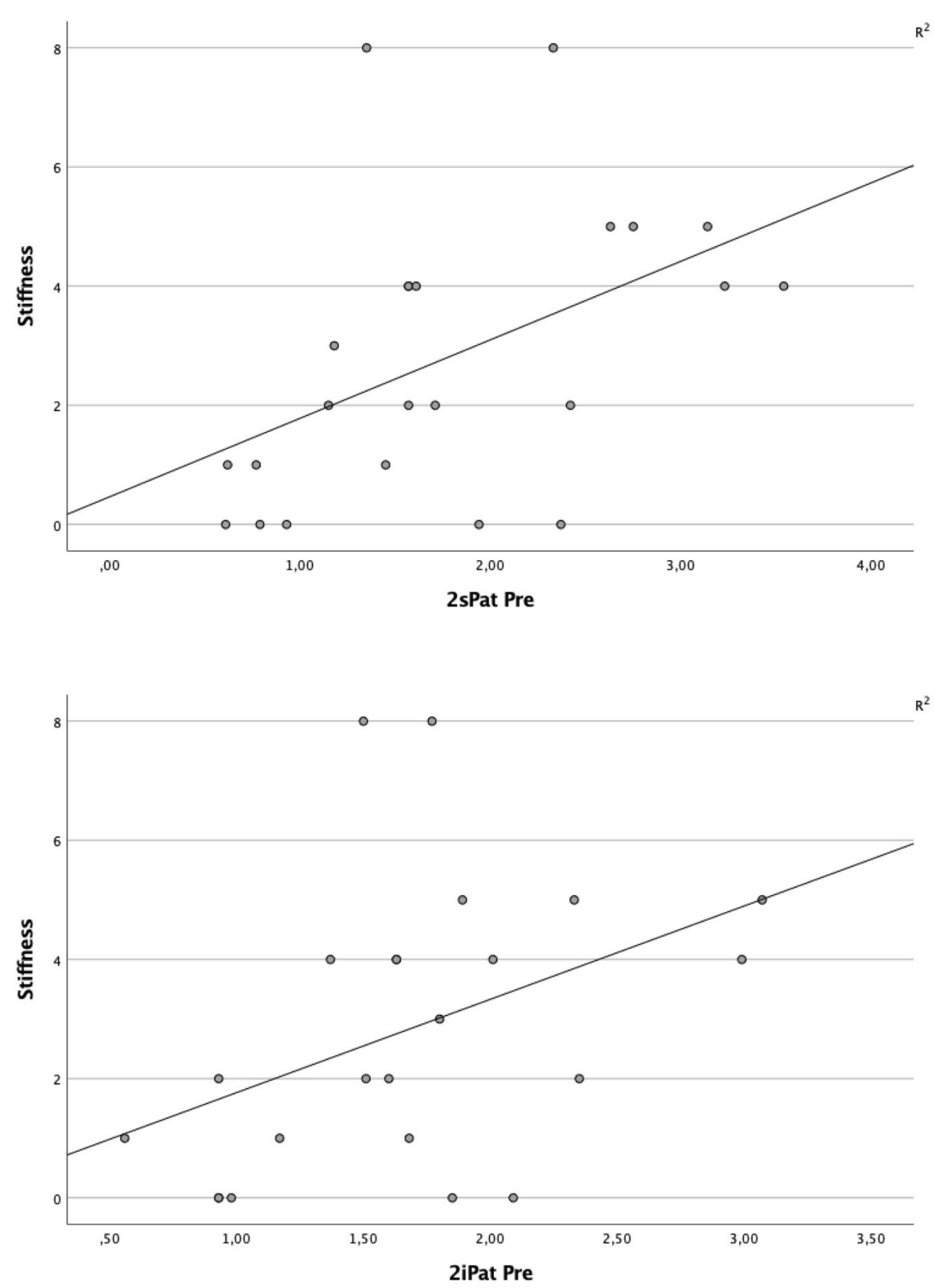

Table 6 Eta-correlations between sex and WOMAC

\begin{tabular}{llc}
\hline & $r=$ & $p=$ \\
\hline Total WOMAC mean/sex & 0.12 & $\mathrm{~ns}$ \\
Daily activities mean/sex & 0.17 & $\mathrm{~ns}$ \\
Pain mean/sex & 0.12 & $\mathrm{~ns}$ \\
Stiffness mean/sex & 0.08 & $\mathrm{~ns}$ \\
\hline
\end{tabular}

$(p=0.008)$. The inferior medial area of the patella (2iPat) correlated with stiffness rho $=0.43(p=0.041)$.

\section{Correlation between demographics and clinical outcome}

Comparisons between age, gender and WOMAC did not show a significant correlation (Tables 6, 7).
Table 7 Spearman correlations between age and WOMAC

\begin{tabular}{|c|c|c|c|c|c|c|}
\hline & & & Pain mean & Stiffness mean & $\begin{array}{l}\text { Daily } \\
\text { activities } \\
\text { mean }\end{array}$ & $\begin{array}{l}\text { Total } \\
\text { Womac } \\
\text { mean }\end{array}$ \\
\hline Spearman-Rho & Age OP & $\begin{array}{l}\text { rho }= \\
\text { Two- tailed } p \text { value }\end{array}$ & $\begin{array}{l}-0.09 \\
\mathrm{~ns}\end{array}$ & $\begin{array}{l}0.13 \\
\mathrm{~ns}\end{array}$ & $\begin{array}{l}-0.02 \\
\mathrm{~ns}\end{array}$ & $\begin{array}{l}-0.03 \\
\text { ns }\end{array}$ \\
\hline
\end{tabular}




\section{Discussion}

The most important findings of this study were the following three:

Firstly, preoperative elevated BTU values in the patellar region correlated significantly with a worse clinical outcome. It was previously shown that MOWHTO leads to an increase of the contact pressure in the patellofemoral joint (PFJ) [15, 19, 20, 25, 37, 39]. Kim et al. [19] suggested that the increased loading of the PFJ may be the cause of postoperative pain and be associated with the development and progression of OA in the PFJ. As a matter of fact, several studies were able to show that patellofemoral OA in knees after MOWHTO is progressive on both radiological imaging and knee arthroscopy [4, 24, 41]. Song et al. [36] reported in a study that patients with underlying patellofemoral cartilage degeneration at the time of HTO were particularly affected by the progression of cartilage defects and had a worse clinical outcome compared to patients without such pre-existing cartilage degeneration. A rho of 0.43 can be interpreted as a moderate correlation and leads to a determination coefficient of 0.18 . Thus, assuming a causal relationship, the present study shows that increased preload in the superior lateral region of the patella could explain up to $18 \%$ of the variance in pain. However, it should be noted that the correlations calculated do not prove a causal relationship between the BTU and WOMAC score [32]. Moreover, as the WOMAC was not collected preoperatively but only postoperatively, it is not clear whether the worse clinical outcome is related to the surgery or not. It cannot be ruled out that the postoperative pain and resulting functional limitations are the normal consequence of progression of pre-existing patellofemoral OA and have not been negatively affected by MOWHTO. However, considering the results of this study in the light of the current literature, it can be assumed that patients with an increased preload in the PFJ are at greater risk for a worse outcome and that the indication for MOWHTO should not be established in patients with an increased load pattern in the PFJ or even osteoarthritis in the PFJ.

Secondly, the hypothesis that clinical outcome is related to alignment correction could not be confirmed. This contradicts the findings of Hernigou, and others [2, 10], who were able to show that both under- and overcorrection of the limb alignment are associated with an inferior outcome. Moreover, recent studies have found negative effects of overcorrection on the progression of patellofemoral OA, which is also in contrast to the findings of our study [4, 24, $29,41]$. However, the reason for our contradictory results could lie in the rather short follow-up period of 2 years, as the studies mentioned above indicate a deterioration after about 7 years $[5,10]$.

Thirdly, contrary to the results in the literature, no correlation was found between age and outcome [8]. In contrast to the results of van Raaij et al., male gender had no influence on the clinical outcome [40]. However, the results of the present study are only of limited significance due to the small sample size.

Regarding the results of the present study, several limitations must be considered when interpreting the data. In particular, the small number of patients could be a reason for the lack of correlation between preloading of the lateral compartment, the preoperative mechanical axis and the clinical outcome. The second major limitation is that the clinical outcome was only assessed once postoperatively and not preoperatively. Therefore, the clinical outcome of the subjects can only be compared with each other to a limited extent. Moreover, important confounding factors such as patient weight and weight change over time were not recorded, although it has been shown that obese patients with deformities are disproportionately affected by the development and progression of OA [3]. For future studies, it would be advisable to address these issues. It is also known that patient satisfaction and clinical outcome change over time and certain complications occur only after an interval of several years $[5,6,10]$. Therefore, the follow-up time of 24 months in the present study can be considered as questionably short and follow-up studies are advised to consider a longer follow-up period. Moreover, an interesting aspect for future studies would be to see how many of the patients who underwent MOWHTO had a conversion to TKA during follow-up, and to evaluate the preoperative SPECT/CT in these patients for specific loading pattern.

Thus, according to the results of the present study, conducting a preoperative SPECT/CT scan may help the treating surgeons in their day-to-day work to decide which patients would be better recommended for an alternative treatment method due to the risk of a worse clinical outcome. However, as promising as the possible use of SPECT/CT as a predictive tool seems, it needs to be investigated in further studies.

\section{Conclusion}

This study highlights the role of preoperative SPECT in modern knee surgery to obtain information about the loading pattern on different compartments of the knee. Despite its limitations, this study could help surgeons on a routine basis by identifying patients in whom special care is required. In patients with increased BTU in the patellar region, the indication for MOWHTO should be made with all due caution 
and possible alternative treatment options should be evaluated to avoid dissatisfied patients.

Acknowledgements We thank Silvia Reichl, who contributed to data collection and data management. We thank the clinicians who participated in the follow-up and WOMAC score surveys.

Author contributions BS and MH designed the study. The SPECT/CT scans used for the study were performed under the supervision of HR. FA and BS performed the statistical data analysis. BS and $\mathrm{MH}$ wrote the manuscript. All authors interpreted the data, critically reviewed the work, made important contributions to the manuscript with their suggestions for improvement, approved the final version, and agreed to be responsible for all aspects of the work.

Funding Open Access funding provided by Universität Basel (Universitätsbibliothek Basel). The study was sponsored by the research fund of the Department of Orthopaedic Surgery and Traumatology of the Cantonal Hospital Baselland and the research group "DKF Knee" of the University of Basel.

\section{Declarations}

Conflict of interest The authors did not receive any benefits or funding from any commercial party related to the subject of this article.

Ethical approval The study was approved by the local ethical committee and was performed in accordance with the ethical standards of the responsible committee and with the guidelines of the Helsinki Declaration of 1975, as revised in 2008.

Informed consent A written informed consent was signed by every patient.

Open Access This article is licensed under a Creative Commons Attribution 4.0 International License, which permits use, sharing, adaptation, distribution and reproduction in any medium or format, as long as you give appropriate credit to the original author(s) and the source, provide a link to the Creative Commons licence, and indicate if changes were made. The images or other third party material in this article are included in the article's Creative Commons licence, unless indicated otherwise in a credit line to the material. If material is not included in the article's Creative Commons licence and your intended use is not permitted by statutory regulation or exceeds the permitted use, you will need to obtain permission directly from the copyright holder. To view a copy of this licence, visit http://creativecommons.org/licenses/by/4.0/.

\section{References}

1. Bonasia DE, Dettoni F, Sito G, Blonna D, Marmotti A, Bruzzone $\mathrm{M}$ et al (2014) Medial opening wedge high tibial osteotomy for medial compartment overload/arthritis in the varus knee: prognostic factors. Am J Sports Med 42:690-698

2. El-Azab HM, Morgenstern M, Ahrens P, Schuster T, Imhoff AB, Lorenz SG (2011) Limb alignment after open-wedge high tibial osteotomy and its effect on the clinical outcome. Orthopedics 34:e622-628

3. Felson DT, Goggins J, Niu J, Zhang Y, Hunter DJ (2004) The effect of body weight on progression of knee osteoarthritis is dependent on alignment. Arthritis Rheum 50:3904-3909
4. Goshima K, Sawaguchi T, Shigemoto K, Iwai S, Nakanishi A, Ueoka K (2017) Patellofemoral osteoarthritis progression and alignment changes after open-wedge high tibial osteotomy do not affect clinical outcomes at mid-term follow-up. Arthroscopy 33:1832-1839

5. Goutallier D, Hernigou P, Medevielle D, Debeyre J (1985) Longterm results of the treatment of medial femoro-tibial gonarthrosis by tibial valgisation osteotomy. Outcome of 93 osteotomies after more than 10 years. Rev Rhum Mal Osteoartic 52:437-444

6. Han SB, Lee JH, Kim SG, Cui CG, Suh DW, Lee SY et al (2018) Patient-reported outcomes correlate with functional scores after opening-wedge high tibial osteotomy: a clinical study. Int Orthop 42:1067-1074

7. Han X, Cui J, Xie K, Jiang X, He Z, Du J et al (2020) Association between knee alignment, osteoarthritis disease severity, and subchondral trabecular bone microarchitecture in patients with knee osteoarthritis: a cross-sectional study. Arthritis Res Ther 22:203

8. Hantes ME, Natsaridis P, Koutalos AA, Ono Y, Doxariotis N, Malizos KN (2018) Satisfactory functional and radiological outcomes can be expected in young patients under 45 years old after open wedge high tibial osteotomy in a long-term follow-up. Knee Surg Sports Traumatol Arthrosc 26:3199-3205

9. He M, Zhong X, Li Z, Shen K, Zeng W (2021) Progress in the treatment of knee osteoarthritis with high tibial osteotomy: a systematic review. Syst Rev 10:56

10. Hernigou P, Medevielle D, Debeyre J, Goutallier D (1987) Proximal tibial osteotomy for osteoarthritis with varus deformity. A ten to thirteen-year follow-up study. J Bone Joint Surg Am 69:332-354

11. Hirschmann MT, Schon S, Afifi FK, Amsler F, Rasch H, Friederich NF et al (2013) Assessment of loading history of compartments in the knee using bone SPECT/CT: a study combining alignment and 99mTc-HDP tracer uptake/distribution patterns. J Orthop Res 31:268-274

12. Hirschmann MT, Wagner CR, Rasch H, Henckel J (2012) Standardized volumetric 3D-analysis of SPECT/CT imaging in orthopaedics: overcoming the limitations of qualitative $2 \mathrm{D}$ analysis. BMC Med Imaging 12:5

13. Hohloch L, Kim S, Eberbach H, Izadpanah K, Mehl J, Niemeyer $P$ et al (2019) Improved clinical outcome after medial open-wedge osteotomy despite cartilage lesions in the lateral compartment. PLoS ONE 14:e0224080

14. Hohloch L, Kim S, Mehl J, Zwingmann J, Feucht MJ, Eberbach H et al (2018) Customized post-operative alignment improves clinical outcome following medial open-wedge osteotomy. Knee Surg Sports Traumatol Arthrosc 26:2766-2773

15. Javidan P, Adamson GJ, Miller JR, Durand P Jr, Dawson PA, Pink MM et al (2013) The effect of medial opening wedge proximal tibial osteotomy on patellofemoral contact. Am J Sports Med 41:80-86

16. Jin CS, Song EK, Santoso A, Ingale PS, Choi IS, Seon JK (2020) Survival and risk factor analysis of medial open wedge high tibial osteotomy for unicompartment knee osteoarthritis. Arthroscopy 36:535-543

17. Jonker L, Bell L, Monda M, Murray J, Dawson M (2021) Longer term outcomes following high tibial osteotomy for osteoarthritis: a prospective, multi-centre observational study comparing tomofix and OPTY-LINE devices. Indian J Orthop 55:967-973

18. Kim JH, Kim HJ, Lee DH (2017) Survival of opening versus closing wedge high tibial osteotomy: a meta-analysis. Sci Rep 7:7296

19. Kim KI, Kim DK, Song SJ, Lee SH, Bae DK (2017) Medial openwedge high tibial osteotomy may adversely affect the patellofemoral joint. Arthroscopy 33:811-816

20. Kloos F, Becher C, Fleischer B, Feucht MJ, Hohloch L, Sudkamp N et al (2019) High tibial osteotomy increases patellofemoral pressure if adverted proximal, while open-wedge HTO with 
distal biplanar osteotomy discharges the patellofemoral joint: different open-wedge high tibial osteotomies compared to an extraarticular unloading device. Knee Surg Sports Traumatol Arthrosc 27:2334-2344

21. Kolb W, Guhlmann H, Windisch C, Koller H, Grutzner P, Kolb K (2010) Opening-wedge high tibial osteotomy with a locked lowprofile plate: surgical technique. J Bone Joint Surg Am 92(Suppl 1 Pt 2):197-207

22. Kumar D, Manal KT, Rudolph KS (2013) Knee joint loading during gait in healthy controls and individuals with knee osteoarthritis. Osteoarthritis Cartilage 21:298-305

23. Kuriyama S, Watanabe M, Nakamura S, Nishitani K, Sekiguchi K, Tanaka $\mathrm{Y}$ et al (2020) Classical target coronal alignment in high tibial osteotomy demonstrates validity in terms of knee kinematics and kinetics in a computer model. Knee Surg Sports Traumatol Arthrosc 28:1568-1578

24. Lee SS, So SY, Jung EY, Kim HJ, Lee BH, Wang JH (2019) Predictive factors for patellofemoral degenerative progression after opening-wedge high tibial osteotomy. Arthroscopy 35:1703-1710

25. Moon HS, Choi CH, Jung M, Park SH, Lee DY, Shin JK et al (2019) The effect of medial open wedge high tibial osteotomy on the patellofemoral joint: comparative analysis according to the preexisting cartilage status. BMC Musculoskelet Disord 20:607

26. Mucha A, Dordevic M, Hirschmann A, Rasch H, Amsler F, Arnold MP et al (2015) Effect of high tibial osteotomy on joint loading in symptomatic patients with varus aligned knees: a study using SPECT/CT. Knee Surg Sports Traumatol Arthrosc 23:2315-2323

27. Mucha A, Dordevic M, Testa EA, Rasch H, Hirschmann MT (2013) Assessment of the loading history of patients after high tibial osteotomy using SPECT/CT-a new diagnostic tool and algorithm. J Orthop Surg Res 8:46

28. Niemeyer P, Schmal H, Hauschild O, von Heyden J, Sudkamp NP, Kostler W (2010) Open-wedge osteotomy using an internal plate fixator in patients with medial-compartment gonarthritis and varus malalignment: 3 -year results with regard to preoperative arthroscopic and radiographic findings. Arthroscopy 26:1607-1616

29. Otakara E, Nakagawa S, Arai Y, Inoue H, Kan H, Nakayama Y et al (2019) Large deformity correction in medial open-wedge high tibial osteotomy may cause degeneration of patellofemoral cartilage: a retrospective study. Medicine 98:e14299

30. Peng H, Ou A, Huang X, Wang C, Wang L, Yu T et al (2021) Osteotomy around the knee: the surgical treatment of osteoarthritis. Orthop Surg 13:1465-1473
31. Rasch H, Falkowski AL, Forrer F, Henckel J, Hirschmann MT (2013) 4D-SPECT/CT in orthopaedics: a new method of combined quantitative volumetric 3D analysis of SPECT/CT tracer uptake and component position measurements in patients after total knee arthroplasty. Skeletal Radiol 42:1215-1223

32. Schober P, Boer C, Schwarte LA (2018) Correlation coefficients: appropriate use and interpretation. Anesth Analg 126:1763-1768

33. Sharma L, Song J, Felson DT, Cahue S, Shamiyeh E, Dunlop DD (2001) The role of knee alignment in disease progression and functional decline in knee osteoarthritis. JAMA 286:188-195

34. Smith JO, Wilson AJ, Thomas NP (2013) Osteotomy around the knee: evolution, principles and results. Knee Surg Sports Traumatol Arthrosc 21:3-22

35. Smith TO, Sexton D, Mitchell P, Hing CB (2011) Opening- or closing-wedged high tibial osteotomy: a meta-analysis of clinical and radiological outcomes. Knee 18:361-368

36. Song SJ, Yoon KH, Park CH (2020) Patellofemoral cartilage degeneration after closed- and open-wedge high tibial osteotomy with large alignment correction. Am J Sports Med 48:2718-2725

37. Stoffel K, Willers C, Korshid O, Kuster M (2007) Patellofemoral contact pressure following high tibial osteotomy: a cadaveric study. Knee Surg Sports Traumatol Arthrosc 15:1094-1100

38. Stucki G, Meier D, Stucki S, Michel BA, Tyndall AG, Dick W et al (1996) Evaluation of a German version of WOMAC (Western Ontario and McMaster Universities) Arthrosis Index. Z Rheumatol 55:40-49

39. Tanaka T, Matsushita T, Miyaji N, Ibaraki K, Nishida K, Oka S et al (2019) Deterioration of patellofemoral cartilage status after medial open-wedge high tibial osteotomy. Knee Surg Sports Traumatol Arthrosc 27:1347-1354

40. van Raaij T, Reijman M, Brouwer RW, Jakma TS, Verhaar JN (2008) Survival of closing-wedge high tibial osteotomy: good outcome in men with low-grade osteoarthritis after 10-16 years. Acta Orthop 79:230-234

41. Yoon TH, Choi CH, Kim SJ, Kim SH, Kim NH, Jung M (2019) Effect of medial open-wedge high tibial osteotomy on the patellofemoral joint according to postoperative realignment. Am J Sports Med 47:1863-1873

Publisher's Note Springer Nature remains neutral with regard to jurisdictional claims in published maps and institutional affiliations. 